\title{
A Systematic Review of Digital Behaviour Change Interventions for More Sustainable Food Consumption
}

\author{
Björn Hedin ${ }^{1} * \mathbb{B}$, Cecilia Katzeff ${ }^{2}{ }^{\mathbb{D}}$, Elina Eriksson ${ }^{1}{ }^{\mathbb{D}}$ and Daniel Pargman ${ }^{1}$ \\ 1 KTH Royal Institute of Technology, Department of Media Technology and Interaction Design, \\ SE-100 44 Stockholm, Sweden; elina@kth.se (E.E.); pargman@kth.se (D.P.) \\ 2 KTH Royal Institute of Technology, Department of Strategic Sustainability Studies, SE-100 44 Stockholm, \\ Sweden; ckatzeff@kth.se \\ * Correspondence: bjornh@kth.se
}

Received: 10 April 2019; Accepted: 2 May 2019; Published: 8 May 2019

\begin{abstract}
Food production and consumption present major sustainability challenges, and finding ways to reduce the environmental impact of food, for example through behavioural changes by consumers, is becoming increasingly important. In recent years, digital interventions have become important tools to change behaviours in many areas. In this review, we evaluate the status of current scientific knowledge of digital behaviour change interventions for sustainable food consumption practices. Following the Preferred Reporting Items for Systematic Reviews and Meta-Analyses (PRISMA) checklist for how to conduct systematic reviews, we searched multiple databases for papers containing terms related to food, sustainability and digital behaviour change interventions. Only studies where the digital interventions were actually implemented and evaluated from a behaviour change perspective were included, resulting in 15 primary studies in the final review. The quality of the studies was evaluated from a behaviour change perspective, and the approaches used were categorised using two intervention frameworks, the Behaviour Change Wheel and the Behaviour Change Technique Taxonomy v1. The results show that all of the included studies had major quality issues when evaluated from a behaviour change perspective. This means that we could not find any evidence regarding whether the digital behaviour change interventions examined worked or not. Most studies further lacked theoretical grounding or a clear approach to how or why they should be effective for behaviour change for more sustainable food consumption practices. Our main recommendation for future research in the field is to expand from the current exploratory phase to conducting scientifically rigorous studies of higher quality, more thoroughly grounded in behaviour change theory and methods. Furthermore, based on our study, we suggest changes to the Behaviour Change Technique Taxonomy v1.
\end{abstract}

Keywords: sustainability; food; behaviour change; digital intervention; digital behaviour change; sustainable HCI; human computer interaction; Behaviour Change Wheel; Behaviour Change Technique Taxonomy; systematic review; consumer behaviour

\section{Introduction}

Today, we face significant global sustainability challenges, where the food system is a major area of concern. Food and farming systems contribute up to $30 \%$ of greenhouse gas emissions [1]. Furthermore, food production plays a significant role in the intersection of several planetary boundaries, such as biosphere integrity, land-system changes and biogeochemical flows [2]. Actions causing unnecessary climate and environmental impact occur at all phases of the food chain, including agriculture, processing 
and manufacturing, wholesale and logistics, retail and food services, as well as consumption (storing, cooking, etc.) and waste management. It is clear that the entire food system needs to change in a more sustainable direction [1]. Problems need to be analysed, opportunities for improvement need to be identified, and interventions need to be formulated to change current problematic states to more sustainable ones.

During the last few years, an increasing number of studies have been conducted using digital interventions to alter people's behaviour towards becoming more sustainable. These interventions include various techniques, such as nudging, persuasive technology, visualisation, gamification and eco-feedback (e.g., [3-5]). Many interventions are tied to the contemporary pervasive use of smartphones and apps. The first modern smartphone with the possibility to add apps, Apple's iPhone, was released only a little more than 10 years ago, in 2007. The smartphone-a computer in your pocket-has since become both intimate and ubiquitous. Most people in affluent societies always carry a smartphone with them, and the use of various apps has become widespread. Since food consumption is an everyday activity, the possibility of influencing behaviour through the use of digital technologies in general is appealing. This is understandable, considering the omnipresence of these devices. However, in spite of the growing body of research studies in the area, there is a clear lack of synthesised knowledge about which types of interventions work to influence behaviour towards more sustainable consumption patterns, and which do not.

This article addresses the challenges of behaviour change and how to intervene in unsustainable food consumption practices. The target groups for the interventions in this study are end consumers who, for example, purchase, cook and consume food, and organisations that purchase as well as prepare large amounts of food (e.g., retail/grocery stores and food services such as restaurants and public schools). The paper intends to identify and synthesise knowledge in the area through a systematic literature review. Our review poses the question: What is the status of current scientific knowledge of digital behaviour change interventions for more sustainable food consumption practices? Furthermore, what are the most significant and reliable results in this field? The review aims to include papers at the intersection of ecological sustainability and food consumption behaviours, where "food consumption behaviours" denotes a variety of food-related practices. These include, for instance, behaviour to reduce food waste; switching to a "climate-friendly" food diet [6]; changing practices around food purchases such as replacing car trips to a distant hypermarket with biking to a local supermarket or walking to a neighbourhood grocery store [7,8]; changes in the use of refrigerants (in retail or at home); or changing energy practices around food preparation [9]. Besides the wide set of food consumption behaviours already stated, we include all papers that describe digital behaviour change interventions, such as those involving smartphones, personal digital assistants, wearables, haptic feedback, text messaging, social media, web-based solutions or the Internet of Things, that have been tested on people, where the results have been measured or evaluated, and the paper makes claims about the effects of the intervention in question.

In order to synthesise the studies identified in our review, we used the Behaviour Change Wheel (BCW) $[10,11]$ and the Behaviour Change Technique Taxonomy v1 (BCT) [12] as analytical frameworks. The Behaviour Change Wheel is a framework for characterising and designing behaviour change interventions based on a synthesis of 19 frameworks from several disciplines, including environmental behaviour. The Behaviour Change Technique Taxonomy is a set of 93 distinct behaviour change techniques clustered into 16 groups [12]. Since their creation, the BCW and BCT frameworks have been used extensively to plan and evaluate behavioural change interventions, mainly in health [3], but also in areas such as personal transportation habits [13] and sedentary behaviour [14]. In using these frameworks, we also assess how well they are adapted to the types of studies we found and provide suggestions for how they can be modified to be more useful for future studies on digital behaviour change interventions for sustainability.

In summary, this paper presents a systematic literature review on the status of current scientific knowledge on digital behaviour change interventions for sustainable food consumption practices. This 
contribution is intended to improve the area in order to become more relevant and effective, and thus be valuable for both researchers and practitioners. The paper outline is as follows: in Section 2, we describe the method used in the literature review, which is based on the Preferred Reporting Items for Systematic Reviews and Meta-Analyses (PRISMA) statement [15]. In Section 3, we present the results of our systematic literature review, including an analysis of the papers in our corpus based on BCW and BCT. This is followed by Section 4, where we compare the results to similar studies in other fields, discuss the relationship between behaviour and practice, and then discuss a possible extension of the Behaviour Change Technique Taxonomy based on the results from this study. Finally, we end the paper with conclusions and future work in Section 5.

\section{Method}

The review protocol below was developed by the authors, and it is based on the PRISMA statement for systematic reviews and meta-analyses [15], a well-established guideline used in many systematic reviews. The structure below (Sections 2.1-2.6) follows the PRISMA guidelines.

\subsection{Eligibility Criteria}

We applied the following inclusion and exclusion criteria to the studies identified in the database search:

\section{Inclusion criteria}

- Peer-reviewed papers (including peer-reviewed conference papers)

- Studies describing digital interventions

- Studies describing food-related interventions

- Studies describing interventions aimed at ecological sustainability

- Interventions with the aim of changing behaviour in a broad sense

- Any population

- Any date

- Papers written in English

\section{Exclusion criteria}

- Book chapters

- Works-in-progress or papers labelled as "short papers"

- Design papers

- Digital interventions that have not been implemented

- Interventions that have not been evaluated on potential users from a behaviour change perspective, for example if the evaluation was focused on the user interface

- Interventions covering aspects other than households or large-scale management of food (retail, restaurants, public preparation and consumption of food in school kitchens, hospitals, etc.)

\subsection{Information Sources}

The electronic databases we used in this review were chosen with the assistance of an information specialist librarian. Since the focus of our study was interdisciplinary and spanned the intersection of technology and sustainability, in consultation with the specialist librarian, we chose to search the following 3 databases:

- GreenFILE, since it has a focus on sustainability

- ACM Digital Library, since it has a focus on technology

- Scopus, since it covers a wide range of areas 
The databases were searched between 17 April and 3 May 2018, with a complementary search of the ACM Digital Library on 12 September due to a syntax error in the original search string that led to overly strict constraints. After removing duplicates and applying the inclusion and exclusion criteria, we used backward and forward snowballing to (1) search through the references of all selected papers (backward snowballing) and (2) search for more recent papers that referred to any of the selected papers to find relevant papers that could be included in our corpus (forward snowballing), as per the guidelines supplied by Wohlin [16].

\subsection{Search}

The search terms for the database searches were constructed so that 3 search criteria would be fulfilled for each of the 3 database searches. The first search criterion was that the paper should cover a digital solution, the second that it should cover food and the third that it should cover ecological sustainability. We also added exclusion search terms, such as "agriculture" to exclude the production phase of the food system in databases that allowed this, and keywords found in several unrelated papers that otherwise would have matched our criteria, such as "pyrolysis" and "chromatography". We assumed that all papers from GreenFILE automatically matched the sustainability criterion and that all papers from the ACM Digital Library automatically matched the digital solution criterion. These assumptions led to a larger hit rate from these 2 databases, and this is also part of the reason why more than $90 \%$ of the records identified through the database search could easily be excluded based solely on their titles in the screening step (see Section 3.1). This resulted in the following searches in the databases:

- GreenFILE: (food* OR *meal* OR $\operatorname{cook}^{*}$ ) AND (ICT OR digital OR mobile OR app OR HCI NOT agriculture) (+ Boolean + Scholarly)

- Scopus: TITLE-ABS-KEY (( ${ }^{*} \mathrm{meal}^{*}$ OR $\operatorname{cook}^{*}$ OR food $\left.{ }^{*}\right)$ AND (co2 OR ghg OR green OR climate OR sustainab* OR recycl* OR waste* OR eco-visuali* OR eco-feedback) AND (digital* OR ict OR mobile OR app OR hci)) AND NOT (agriculture OR pyrolysis OR chromatography)

- ACM: "query": \{(food\% OR cook\% OR \%meal\% OR diet $\%$ ) AND (co2 OR ghg OR green OR climate OR sustainab\% OR recycl\% OR waste\% OR environm $\%$ OR eco\}

\subsection{Study Selection}

The papers identified in the database searches were screened in multiple stages using the inclusion and exclusion criteria as follows:

- Each paper was screened by title by at least 2 of the authors, all of whom are experienced in digital tools for sustainability.

- The abstracts of the remaining papers were screened by at least 2 of the authors.

- Two of the authors then downloaded all papers that remained. All peer-reviewed papers (journal and conference) were included, while book chapters, workshop papers, work-in-progress papers and papers labelled as "short papers" were excluded.

- Three or four authors scanned the full-text papers and categorised the remaining papers as having/not having empirical results and being about/not being about food and behaviour change and sustainability.

For all of these steps, any disagreements were resolved through discussions, and the last step sometimes involved 3 or 4 persons spending an entire day reading, discussing and analysing a single article. For the resulting corpus, the authors performed backward and forward snowballing [16] and screened new papers using the same procedure as described above. The snowballing was performed until no further studies could be found. 


\subsection{Data Collection Process}

At least 3 of the authors participated in the data extraction for each paper. A data extraction form was developed specifically for this review as a spreadsheet, informed by the standard data extraction strategies in the Cochrane Handbook of Systematic Reviews [17]. After reviewing a number of papers, some adjustments were made to the form and previously reviewed papers were reassessed. Materials and appendices that were referenced in the papers were consulted for additional information, but we made no attempt to seek additional information from the authors of papers in the corpus. One of the authors of this review was a co-author of one of the reviewed papers (Zapico et al., 2016), and therefore, did not participate in any way in the data extraction or analysis of that paper.

It should be noted that our unit of analysis was digital behaviour change interventions, where each intervention correlates to a study. However, there might not be a one-to-one correlation between studies and papers, since one paper can describe more than one study and one study can be described in more than one paper. During the data extraction process, we found that 2 papers were based on the same dataset, and this was addressed by grouping these papers together. Another paper presented data from 2 different studies and was, in our data extraction process, classified as describing 2 different primary studies. Since our focus was on digital behaviour change interventions, subresults in various papers on additional, nondigital behavioural change interventions were not extracted from these papers.

\subsection{Data Items}

\subsubsection{Study Characteristics}

The data about the study characteristics that were extracted from the studies were as follows: sustainability goal, study aim and objective(s), digital solution, theory, study design and data collection, data analysis, duration of study, sample size and intervention results.

\subsubsection{Quality Assessment}

We reviewed several frameworks for assessing the quality of the studies in our review, but did not find any framework that included both quantitative and qualitative data suitable for our purpose. Hence, we developed an assessment scheme with basic quality criteria to evaluate the quantitative and qualitative conclusions, loosely based on a critique by Brynjarsdottir et al. [5] on similar studies in sustainable human-computer interactions. The evaluation was based on an overall assessment of the data extracted from the papers. The categories we assessed were as follows: measuring before/after or using a baseline, control group, longitudinal follow-up, respondents match target group, substantial quantitative results and substantial qualitative results. For each paper, at least 3 authors independently rated and then discussed their ratings for each category until they reached an agreement. The scale that was used to rate each category was as follows: 0 (not at all), 1 (fulfils category criterion but with low reliability or validity), 2 (fulfils category criterion with reasonable reliability and validity) and 3 (fulfils category criterion with high reliability and validity). Furthermore, we found various additional aspects of the papers that were problematic from the perspective of our review but were not covered by the assessed categories. These undermined our confidence in the results, which led us to include an additional category, which we called "other aggravating circumstances". This category had a scale with the following levels: 0 (major aggravating circumstances), 1 (aggravating circumstances), 2 (minor aggravating circumstances) and 3 (no aggravating circumstances) (see Section 3.3). We hasten to add that this quality assessment is only valid in relation to the focus of this review, and that the papers assessed could well be of high quality with respect to other aims and criteria.

\subsubsection{Intervention Behaviour Change Characteristics}

The data items coded with regard to intervention characteristics are based on the Behaviour Change Wheel models and methods for analysing and designing behaviour change interventions [10] 
and the Behaviour Change Technique Taxonomy v1 [11]. While a full description of these goes beyond the scope of this review, short descriptions are included below.

The first coded item is "target behaviour" (e.g., "use leftover food", "increase reflection in order to reduce food thrown away", etc.). Target behaviours that were explicitly mentioned in a paper were coded and were otherwise inferred from the text through discussions among the researchers who coded the paper. The second coded item is "sources of behaviour", based on the capability, opportunity, motivation, behaviour (COM-B) model [10]. According to the COM-B model, the interactions among these 3 factors are the sources of behaviour, and interventions can be directed towards changing one or several of these factors. Capability is defined as "the individual's psychological and physical capacity to engage in the activity concerned. It includes having the necessary knowledge and skills"; opportunity is defined as "all the factors that lie outside the individual that make the behaviour possible or prompt it"; and motivation is defined as "all those brain processes that energise and direct behaviour, not just goals and conscious decision-making" [10]. These factors are further divided into physical and psychological capabilities, physical and social opportunities, and reflective and automatic motivations, which are the codes that we used. The coding was determined through discussion among the authors coding each paper.

The third coded item is "intervention functions" using the descriptions in the Behaviour Change Wheel [10], which are: education ("Increasing knowledge or understanding"), persuasion ("Using communication to induce positive or negative feelings or stimulate action"), incentivisation ("Creating expectation of reward"), coercion ("Creating expectation of punishment or cost"), training ("Imparting skills"), restriction ("Using rules to reduce the opportunity to engage in the target behaviour (or to increase the target behaviour by reducing the opportunity to engage in competing behaviours)"), environmental restructuring ("Changing the physical or social context"), modelling ("Providing an example for people to aspire to or imitate") and enablement ("Increasing means/reducing barriers to increase capability or opportunity") (p. 7 in [10]). For each intervention, one or several intervention functions were coded after discussions among the researchers coding the paper.

Finally, we coded which Behaviour Change Techniques (BCTs) were used in the interventions based on the Behaviour Change Technique Taxonomy v1 [12], which is described as an "extensive, consensually agreed hierarchically structured taxonomy of techniques" (ibid.). The Behaviour Change Technique Taxonomy v1 consists of 93 techniques (such as "self-monitoring of behaviour" and "instructions on how to perform behaviour"), which are clustered into 16 behaviour change categories (such as "feedback and monitoring" and "shaping knowledge"). For each intervention, one or several $\mathrm{BCTs}$ were coded after discussions among the researchers coding the paper.

\section{Results}

This section is divided by subheadings. It should provide a concise and precise description of the experimental results, their interpretation and the experimental conclusions that can be drawn.

\subsection{Study Selection}

A total of 2039 papers were identified in the initial database searches and another 13 papers were identified through backward and forward snowballing, as described in the Method section. These papers were examined by title, and this resulted in the removal of 1856 papers. For the 196 papers that remained, the abstracts were screened and a further 129 papers were removed. The remaining 67 papers were downloaded and the full texts were screened. Of these, 35 were removed because they were not peer-reviewed (see the corresponding section in the Method section). Furthermore, an additional 17 papers were removed because they lacked an empirical evaluation (see Figure 1 for more details). In the final corpus, 2 papers were grouped together since they were both based on the same primary data (Thieme et al., 2012 and Comber et al., 2013a), and one paper was divided into 2 primary studies (Lim et al., 2017 parts 1 and 2). This resulted in 15 primary studies included in this review (see Appendix A). This is an acceptable level and in line with comparable studies. For comparison, Arnott 
et al. analysed 15 papers out of the 12,826 papers that were initially identified through their database search [13].

\section{PRISMA 2009 Flow Diagram}

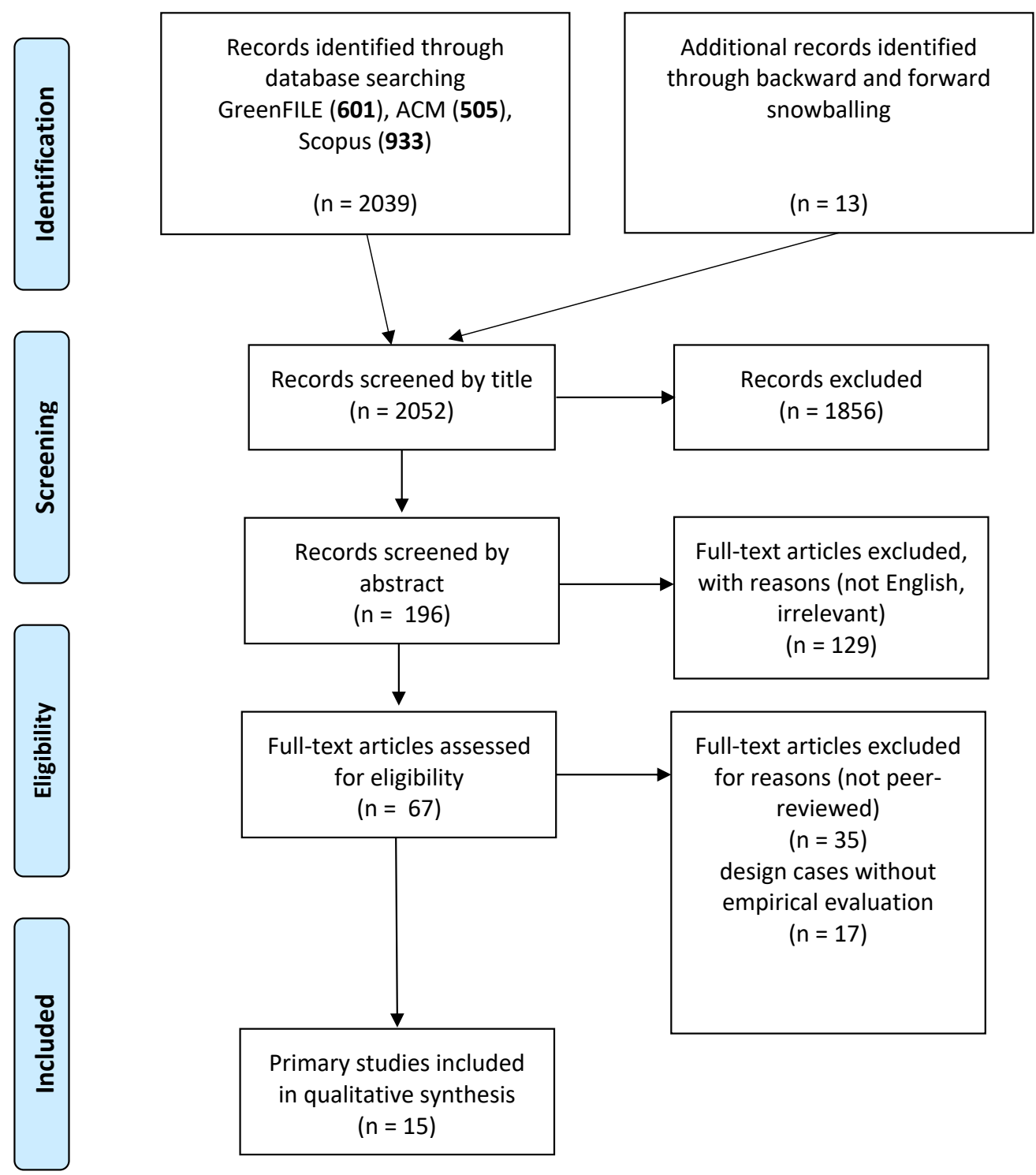

From: Moher D, Liberati A, Tetzlaff J, Altman DG, The PRISMA Group (2009). Preferred Reporting /tems for Systematic Reviews and MetaAnalyses: The PRISMA Statement. PLoS Med 6(7): e1000097. doi:10.1371/journal.pmed1000097

For more information, visit www.prisma-statement.org.

Figure 1. Flow diagram of studies included in the review. PRISMA, Preferred Reporting Items for Systematic Reviews and Meta-Analyses. 


\subsection{Study Characteristics}

Table 1 presents sustainability goal, study aim/objectives, target behaviour, digital intervention(s) and intervention results. Out of the 15 papers in our corpus 12 had the sustainability goal of reducing food waste, one had the goal of improving disposal of cooking oil, one had the goal of reducing energy used for cooking food and, one had the goal of increasing organic food purchases. All papers deal with households, except Bandyopadhyay and Dalvi (2017), which instead aims at reducing individuals' food waste at a university food canteen. The papers covered a wide variety of target behaviours and many of them were aimed at raising awareness and prompting reflections on food waste, increasing food supply knowledge or encouraging the sharing of (leftover) food. The studies covered a variety of digital interventions, such as smartphone apps, social media, (internet-connected) smart bins, public interactive screens and food inventory systems. Notably, several studies explored more than one digital solution, making it hard to discern a specific system with a specific impact in terms of results. In terms of intervention results, many of the studies reported unclear results, and the studies mostly reported increased awareness, but did not report any clear results in terms of actual behavioural change. It should finally be noted that none of the studies included an evaluation of the possible negative sustainability effects that could be caused by the technology itself, e.g., in the form of e-waste.

Table 2 presents theory (behaviour change theories used), data collection, data analysis, duration and sample size. Most studies lacked a clear theoretical grounding in terms of using a behavioural change theory. In the four studies, where a theory (in a broad sense) was introduced, that theory was not used to later interpret and discuss the results of the study in question. Table 1 indicates that these studies primarily focused on implementation of the proposed solution (e.g., a system, a gadget or a service) rather than on evaluating the actual behavioural change(s) caused by the proposed solution or applying or evaluating underlying theories of behavioural change (see Table 3). Table 3 further shows that the studies span a wide range of data collection methods, out of which seven studies included some form of pre/post testing, mostly through questionnaires. Many of the studies collected some form of qualitative data, where the data analysis most often consisted of thematic analysis. Some studies collected quantitative data that was analysed mostly through very basic statistical analysis. Notably, four studies did not explicitly describe the analysis made, but only reported on the results. Study duration ranged from onetime use (Pohl et al., 2017) to 18 months of deployment (Ganglbauer et al., 2015), with most studies spanning a period of three to five weeks. One exception is the study by Bandyopadhyay and Dalvi (2017), which states only that their intervention was deployed during "a limited period of time". The sample sizes in the studies were generally low. Eight studies had 65 individuals or fewer and only 5 studies had 188 or more individuals. Two studies did not report on the sample size; Woolley et al. (2016) did not report how many respondents took part in their study, but spoke only in general terms ("a small number of consumers"), and Ganglbauer et al. (2015) reported on how many persons downloaded their app, but did not report on the number of persons who actually used it. 
Table 1. Included papers, part 1.

\begin{tabular}{|c|c|c|c|c|c|}
\hline Study & Sustainability Goal & Study Aim and Objective(s) & Target Behaviour(s) & Digital Intervention(s) & Intervention Results \\
\hline $\begin{array}{l}\text { Bandyopadhyay and } \\
\text { Dalvi } 2017\end{array}$ & Reduce food waste & $\begin{array}{l}\text { Use an interactive installation to reduce food } \\
\text { waste }\end{array}$ & $\begin{array}{l}\text { Reduce the amount of food } \\
\text { that is thrown away as plate } \\
\text { waste in canteen. }\end{array}$ & Public interactive screen & $\begin{array}{l}\text { No measured reduction in food } \\
\text { waste but post survey results } \\
\text { indicate increased motivation and } \\
\text { awareness }\end{array}$ \\
\hline Comber et al., 2013 & Reduce food waste & $\begin{array}{l}\text { Two research questions: How can we further } \\
\text { engage participants in discussion around } \\
\text { recycling? How can we promote engagement } \\
\text { with social media as a means to facilitate this } \\
\text { discussion? }\end{array}$ & $\begin{array}{l}\text { Increase discussions about } \\
\text { food waste }\end{array}$ & $\begin{array}{l}\text { Internet-connected bin } \\
\text { uploading images to a } \\
\text { Facebook app, supporting } \\
\text { challenges, competition across } \\
\text { households, visualisations for } \\
\text { reflection, comparisons with } \\
\text { other bincam users. }\end{array}$ & $\begin{array}{l}\text { Unclear, pre- and post- } \\
\text { questionnaires revealed little } \\
\text { change in participants' attitudes to } \\
\text { recycling and food waste, authors } \\
\text { argue there were some significant } \\
\text { changes in social aspects of } \\
\text { recycling. }\end{array}$ \\
\hline $\begin{array}{l}\text { Farr-Wharton et al., } \\
\text { 2014a }\end{array}$ & Reduce food waste & $\begin{array}{l}\text { How can situated interventions targeting the } \\
\text { domestic fridge provide users with improved } \\
\text { food supply and location awareness to } \\
\text { encourage changes towards sustainable food } \\
\quad \text { practices? } \\
\text { NOTE: one of two intervention were non-digital, } \\
\text { we have only evaluated the digital intervention. }\end{array}$ & $\begin{array}{l}\text { Decrease uncessesary food } \\
\text { purchases (to reduce food } \\
\text { stockpiling) by increasing } \\
\text { food supply awareness }\end{array}$ & Camera and smart phone & Did not lead to any clear results. \\
\hline $\begin{array}{l}\text { Farr-Wharton et al., } \\
\text { 2014b }\end{array}$ & Reduce food waste & $\begin{array}{l}\text { How can mobile applications help facilitate food } \\
\text { sharing and improve consumer knowledge } \\
\text { regarding food supply, location and literacy to } \\
\text { promote changes towards more sustainable food } \\
\text { practices within domestic environments? }\end{array}$ & $\begin{array}{l}\text { Use leftover food; share } \\
\text { excess food }\end{array}$ & $\begin{array}{c}3 \text { apps; Fridge Pal, } \\
\text { LeftoverSwap and EatChaFood }\end{array}$ & $\begin{array}{l}\text { Not so clear-Many small detailed } \\
\text { qualitative results but based on } \\
\text { small number of users. }\end{array}$ \\
\hline Fujita et al., 2014 & $\begin{array}{l}\text { Better disposal of } \\
\text { household cooking } \\
\text { oil }\end{array}$ & $\begin{array}{l}\text { Can an app for visualising GHG emissions from } \\
\text { cooking oil disposal influence users to recycle } \\
\text { more cooking oil? }\end{array}$ & $\begin{array}{c}\text { Increase participation in a } \\
\text { waste cooking oil disposal } \\
\text { program. }\end{array}$ & $\begin{array}{c}\text { Mobile questionnaire on } \\
\text { cooking oil use and disposal } \\
\text { with personalised feedback on } \\
\text { GHG emissions. }\end{array}$ & $\begin{array}{l}\text { Not measured or studied in other } \\
\text { ways. }\end{array}$ \\
\hline $\begin{array}{l}\text { Ganglbauer et al., } \\
2015\end{array}$ & Reduce food waste & $\begin{array}{l}\text { Make (motivated) people reflect on their food } \\
\text { waste through the use of a food waste diary app. }\end{array}$ & $\begin{array}{l}\text { Increase reflection on } \\
\text { personal food waste practices. }\end{array}$ & $\begin{array}{l}\text { App (downloadable for } \\
\text { Android and IOS devices) }\end{array}$ & Unclear \\
\hline $\begin{array}{l}\text { Lim et al., } 2017 \\
\text { Part } 1\end{array}$ & Reduce food waste & $\begin{array}{l}\text { How effective is community-based social recipes } \\
\text { for reducing household food waste and how can } \\
\text { such a system be designed. }\end{array}$ & $\begin{array}{l}\text { Use groups' collective food } \\
\text { resources for sharing, cooking } \\
\text { and eating together. }\end{array}$ & $\begin{array}{l}\text { Food inventory system }+ \text { social } \\
\text { recipes (sent via whatsapp) }\end{array}$ & $\begin{array}{l}\text { No claims of actual behavior change } \\
\text { Some claims of raised awareness. }\end{array}$ \\
\hline $\begin{array}{l}\text { Lim et al., } 2017 \\
\text { Part } 2\end{array}$ & Reduce food waste & $\begin{array}{l}\text { How effective is measuring food waste } \\
\text { combined with eco-feedback for reducing } \\
\text { household food waste. }\end{array}$ & $\begin{array}{l}\text { Un-specific reduction of } \\
\text { organic household waste by } \\
\text { weight. }\end{array}$ & $\begin{array}{c}\text { Smartbin with eco-feedback } \\
\text { including social comparison on } \\
\text { a tablet }\end{array}$ & $\begin{array}{l}\text { Increased awareness. Increased } \\
\text { motivation by social comparison. }\end{array}$ \\
\hline
\end{tabular}


Table 1. Cont.

\begin{tabular}{|c|c|c|c|c|c|}
\hline Study & Sustainability Goal & Study Aim and Objective(s) & Target Behaviour(s) & Digital Intervention(s) & Intervention Results \\
\hline Oliveria et al., 2016 & $\begin{array}{l}\text { Reduce energy used } \\
\text { for cooking food. }\end{array}$ & $\begin{array}{l}\text { Design and evaluate an intervention that } \\
\text { modifies time perception as a strategy to } \\
\text { promote sustainable behaviours }\end{array}$ & $\begin{array}{l}\text { Optimise energy use in } \\
\text { different stages of cooking } \\
\text { food. }\end{array}$ & $\begin{array}{l}\text { Cooking assistant app that } \\
\text { reduces unnecessary energy use } \\
\text { by providing step-wise cooking } \\
\text { instructions and by providing } \\
\text { entertainment to reduce } \\
\text { boredom during waiting. }\end{array}$ & $\begin{array}{l}\text { Mean energy use reduced by } 6.7 \% \\
\text { but not statistically significant } \\
(p=0.27) \text {. Temporal tension was } \\
\text { reduced. }\end{array}$ \\
\hline Pohl et al., 2017 & Reduce food waste & $\begin{array}{l}\text { Increase food sharing using a "cooling station } \\
\text { for food sharing in public spaces", primarily by } \\
\text { making food sharing available at odd hours. }\end{array}$ & $\begin{array}{l}\text { Donate and withdraw food } \\
\text { from a public food-kiosk } \\
\text { station. }\end{array}$ & $\begin{array}{l}\text { Interactive screen on public } \\
\text { cooling station }\end{array}$ & $\begin{array}{l}\text { Participants positive to the cooling } \\
\text { station. }\end{array}$ \\
\hline $\begin{array}{l}\text { Thieme et al., } 2012 \\
\text { Comber and Thieme } \\
2013\end{array}$ & Reduce food waste & $\begin{array}{l}\text { Explore strategies to facilitate reflection and } \\
\text { behavioural change through digital design. The } \\
\text { specific application area was recycling and food } \\
\text { waste. }\end{array}$ & $\begin{array}{l}\text { Increase reflection on food } \\
\text { waste practices. }\end{array}$ & $\begin{array}{l}\text { Internet-connected bin } \\
\text { uploading images to a } \\
\text { Facebook app }\end{array}$ & $\begin{array}{l}\text { Qualitative evaluations showed } \\
\text { increased awareness on food waste. } \\
\text { No statistical findings presented. }\end{array}$ \\
\hline Woolley et al., 2016 & Reduce food waste & $\begin{array}{l}\text { To develop and test a inventory management } \\
\text { system for households in order to reduce } \\
\text { householde food waste. App includes stock list, } \\
\text { expiry date tracker and recipe recommendation. } \\
\text { The expiry date tracker seems to be the only } \\
\text { thing tested. }\end{array}$ & $\begin{array}{l}\text { Use food with near-future } \\
\text { expiry dates. }\end{array}$ & $\begin{array}{l}\text { App (for registering expiry date } \\
\text { and pushing reminders) }\end{array}$ & State $34 \%$ less food waste \\
\hline Young et al., 2017 & Reduce food waste & $\begin{array}{l}\text { Will a social influence intervention approach be } \\
\text { effective at encouraging behaviour change on } \\
\text { social media compared to information } \\
\text { interventions and a control group? }\end{array}$ & $\begin{array}{l}\text { Reduce leftovers from } \\
\text { cooking, improve food } \\
\text { storage methods, use leftover } \\
\text { food }\end{array}$ & $\begin{array}{l}\text { Social media campaign, } \\
\text { e-newsletter }\end{array}$ & $\begin{array}{l}\text { No major differences between the } \\
\text { different groups (facebook, } \\
\text { e-newsletter, magazine, none) }\end{array}$ \\
\hline Young et al., 2018 & Reduce food waste & $\begin{array}{l}\text { "to test the effectiveness of Asda's } \\
\text { communication channels using standard food } \\
\text { reduction messaging in reducing food waste of } \\
\text { customers" }\end{array}$ & $\begin{array}{l}\text { Reduce leftovers from } \\
\text { cooking, improve food } \\
\text { storage methods, use leftover } \\
\text { food }\end{array}$ & $\begin{array}{l}\text { Social media (Facebook) } \\
\text { campaign, e-newsletter, } \\
\text { magazine (online) }\end{array}$ & $\begin{array}{l}\text { They claim that the interventions } \\
\text { did lead to recuded household food } \\
\text { waste, however, results can be } \\
\text { interpreted otherwise }\end{array}$ \\
\hline Zapico et al., 2016 & $\begin{array}{l}\text { Increase organic } \\
\text { food purchases }\end{array}$ & $\begin{array}{l}\text { Explore and evaluate visualisation of food } \\
\text { purchase data to increase consumers' purchase } \\
\text { of organic food }\end{array}$ & $\begin{array}{l}\text { Increase organic food } \\
\text { purchases. }\end{array}$ & $\begin{array}{l}\text { Web page visuallising organic } \\
\text { vs total food purchase data, also } \\
\text { including suggestions to } \\
\text { exchange five products with } \\
\text { greatest impact. }\end{array}$ & $\begin{array}{l}23 \% \text { increase in organic food } \\
\text { purchases }\end{array}$ \\
\hline
\end{tabular}


Table 2. Included papers, part 2.

\begin{tabular}{|c|c|c|c|c|c|}
\hline Study & Theory & Data Collection & Data Analysis & Duration & Sample Size \\
\hline $\begin{array}{l}\text { Bandyopadhyay and } \\
\text { Dalvi } 2017\end{array}$ & $\begin{array}{l}\text { Fogg's behaviour model } \\
\text { for persuasive design }\end{array}$ & $\begin{array}{l}\text { Pre-, during and post food weight } \\
\text { data. Online survey (15 closed + } \\
2 \text { open-ended questions) }\end{array}$ & $\begin{array}{c}\text { Basic statistical analysis of food } \\
\text { waste data (individual + total), } \\
\text { statistical analysis of survey. } \\
\text { Descriptive analysis of qualitative } \\
\text { data. }\end{array}$ & $\begin{array}{l}\text { Unknown (limited period } \\
\text { of time) }\end{array}$ & $\begin{array}{l}2000 \text { people eating in a } \\
\text { student diner (for the } \\
\text { qualitative measurement } \\
\text { of food waste); } \\
200-250 \text { university } \\
\text { students answered } \\
\text { questionnaire }\end{array}$ \\
\hline Comber et al., 2013 & $\begin{array}{c}\text { None explicit. Mentions } \\
\text { for example Flow, but do } \\
\text { not discuss it. }\end{array}$ & $\begin{array}{l}\text { Pre-post test: questionnaires, Focus } \\
\text { groups, interviews }\end{array}$ & $\begin{array}{c}\text { Reports from interviews and focus } \\
\text { groups (analysis method unclear). } \\
\text { Basic statistical analysis of } \\
\text { questionnaire }\end{array}$ & 6 weeks & $\begin{array}{c}6 \text { households, a total of } 34 \\
\text { participants }\end{array}$ \\
\hline Farr-Wharton et al., 2014a & $\begin{array}{l}\text { None explicit (but refers } \\
\text { to persuasion, } \\
\text { gamification etc.) }\end{array}$ & $\begin{array}{l}\text { Design evaluation: photographs, } \\
\text { interviews, diary, observation, } \\
\text { dedicated trash bin }\end{array}$ & Not described & 4 weeks & 4 households \\
\hline Farr-Wharton et al., 2014b & None explicit & $\begin{array}{l}\text { Small sample qualitative study; } \\
\text { observations, interviews }\end{array}$ & Thematic analysis & 3 weeks & $\begin{array}{l}4+4+7 \text { with an overlap } \\
\text { so a total of } 12 \text { individuals }\end{array}$ \\
\hline Fujita et al., 2014 & None & Digital questionnaire. & $\begin{array}{l}\text { Basic statistics of quantitative } \\
\text { questionnaire results. }\end{array}$ & One time use & $\begin{array}{l}\text { Mothers or maids for } \\
188 \text { highschool students. }\end{array}$ \\
\hline Ganglbauer et al., 2015 & $\begin{array}{l}\text { Refers generally to } \\
\text { Reflection in Action by } \\
\text { Donald Schön. }\end{array}$ & Case study: text entries from diaries & Thematic analysis, qualitative & 18 months & $\begin{array}{l}843 \text { entries-Unclear how } \\
\text { many unique users } \\
\text { (downloaded by 1065) }\end{array}$ \\
\hline Lim et al., 2017 Part 1 & None explicit & $\begin{array}{l}\text { Post-study questionnaire Logging } \\
\text { WhatsApp conversations as } \\
\text { response to recipe suggestions in } \\
\text { WhatsApp. }\end{array}$ & $\begin{array}{l}\text { Thematic analysis of WhatsApp } \\
\text { conversations and qualitative } \\
\text { questionnaire results. Comparisons } \\
\text { of Likert-question results. }\end{array}$ & 1 month & $\begin{array}{l}4 \text { groups with a total of } \\
15 \text { individuals }\end{array}$ \\
\hline Lim et al., 2017 Part 2 & None explicit & $\begin{array}{l}\text { Logging of food waste using a } \\
\text { smart bin. Logging WhatsApp } \\
\text { conversations as response to recipe } \\
\text { suggestions in WhatsApp. }\end{array}$ & $\begin{array}{l}\text { Thematic analysis of qualitative } \\
\text { questionnaire results. Comparisons } \\
\text { of Likert-question results. }\end{array}$ & 1 month & $\begin{array}{l}2 \text { groups of a total of } \\
9 \text { individuals }\end{array}$ \\
\hline Oliveria et al., 2016 & $\begin{array}{l}\text { Fogg's behaviour model } \\
\text { for persuasive design; } \\
\text { Theories on time } \\
\text { perception and Flow }\end{array}$ & $\begin{array}{l}\text { Within-subject design. Data } \\
\text { collection by measuring energy use, } \\
\text { questionnaires and by interviews. }\end{array}$ & $\begin{array}{l}\text { Statistical analysis and thematic } \\
\text { analysis }\end{array}$ & $1+1$ days, $\mathrm{A} / \mathrm{B} \mathrm{B} / \mathrm{A}$ & 12 \\
\hline
\end{tabular}


Table 2. Cont.

\begin{tabular}{|c|c|c|c|c|c|}
\hline Study & Theory & Data Collection & Data Analysis & Duration & Sample Size \\
\hline Pohl et al., 2017 & None explicit & $\begin{array}{l}\text { Design prototype (partly mockup). } \\
\text { Questionnaire answers from people } \\
\text { testing the prototype. }\end{array}$ & $\begin{array}{l}\text { Not explicit, reports percent of the } \\
\text { respondents who answered in a } \\
\text { questionnaire. }\end{array}$ & One time use & 303 individuals \\
\hline $\begin{array}{l}\text { Thieme et al., } 2012 \\
\text { Comber and Thieme } 2013\end{array}$ & $\begin{array}{l}\text { Theory of planned } \\
\text { behavior and } \\
\text { Transtheoretical model } \\
\text { (TTM). However, these } \\
\text { are then not used in } \\
\text { interpreting the results or } \\
\text { in the discussion. }\end{array}$ & $\begin{array}{c}\text { Pre-posttest: survey, Focus groups: } \\
\text { audio recording }\end{array}$ & $\begin{array}{l}\text { Thematic analysis of focus groups. } \\
\text { Basic statistical analysis of } \\
\text { questionnaire, but reports only that } \\
\text { there were no significant results } \\
\text { and therefore are not included in } \\
\text { discussion/analysis. }\end{array}$ & 5 weeks & $\begin{array}{l}4 \text { households of } \\
5-7 \text { people living together, } \\
22 \text { individuals in total. }\end{array}$ \\
\hline Woolley et al., 2016 & None stated & Pre-post testing; unknown & Not described & 1 week & $\begin{array}{l}\text { Unknown (Small number of } \\
\text { consumers) }\end{array}$ \\
\hline Young et al., 2017 & Social Influence Theory & $\begin{array}{l}\text { Pre-post testing, quantitative: } \\
\text { survey }\end{array}$ & Statistical analysis & 5 months & 2018 individuals \\
\hline Young et al., 2018 & $\begin{array}{l}\text { Implicit use/reference to } \\
\text { Environmental } \\
\text { Psychology }\end{array}$ & $\begin{array}{l}\text { Pre-post testing, quantitative: } \\
\text { survey }\end{array}$ & Statistical analysis & $\begin{array}{l}11 \text { months (short } \\
\text { "interventions" during } \\
\text { this time period, } \\
6 \text { questionnaires during a } \\
\text { period of } 22 \text { months) }\end{array}$ & 631 individuals \\
\hline Zapico et al., 2016 & Non explicit & $\begin{array}{l}\text { Pre-post testing, quantitative: } \\
\text { logging of purchase data, survey }\end{array}$ & $\begin{array}{l}\text { Basic statistical analysis and } \\
\text { thematic analysis of interviews }\end{array}$ & 5 months & $\begin{array}{l}65 \text { employee at grocery } \\
\text { store }\end{array}$ \\
\hline
\end{tabular}




\subsection{Quality Assessment}

An overall assessment of the quality of the studies is presented in Table 3. As can be easily discerned, all primary studies scored low according to our categories for assessing quality (measures before/after/baseline, control group, waste measured, longitudinal follow-up, respondents match the target group, substantial quantitative results, substantial qualitative results, other aggravating circumstances). As previously noted, our quality assessment is only valid with respect to the focus of this review, and the papers could have been of high quality with respect to other aims and criteria. Perhaps most notable in the table is that only two of the studies included some kind of control group. Also notable is that with the exception of the studies by Bandyopadhyay and Dalvi (2017) and Zapico et al. (2016), no study reliably measured changes in behaviour. Furthermore, there are no reliable longitudinal follow-up measurements in any of the studies, which makes it difficult to answer whether any changes in behaviour were actually sustained over time. Moreover, almost all of the studies had "major aggravating" or "aggravating" circumstances, which undermines our confidence in the results reported. Examples of aggravating circumstances include the following: there were not only few respondents, but they were recruited among friends or colleagues (Farr-Wharton et al., 2014a); some of the respondents took part in several consecutive studies, and there was no discussion of how that might have affected the results (Farr-Wharton et al., 2014b); there was no discussion of how the measurement itself (e.g., 6 consecutive questionnaires on food waste over a period of 22 months) affected respondents' answers, which potentially could have had a larger impact than the digital information campaigns evaluated (Young et al., 2018); they asked for categories in which food had been wasted (but without asking about the quantity of food wasted in each category) and then deduced how much food waste was reduced due to the intervention and calculated monetary savings (Young et al., 2018); and there was a biased sample of respondents (already knowledgeable and potentially highly engaged participants at a sustainability/garbage festival) who answered hypothetical questions (Pohl et al., 2017).

\subsection{Intervention Behaviour Change Characteristics}

Each of the 15 studies addressed between one and four (median $=2$, average $=2.07, \mathrm{SD}=1.22$ ) of the sources of behaviour defined in the COM-B model (Michie et al., 2011). The most common source of behaviour to address was physical opportunity $(n=8)$, followed by psychological capability $(n=7)$, reflective motivation $(n=7)$, automatic motivation $(n=5)$ and social opportunity $(n=4)$. No study addressed physical capability (see Table 4).

Each of the 15 studies addressed between one and three (median $=3$, average $=2.33, \mathrm{SD}=0.90$ ) of the nine intervention functions defined in the Behaviour Change Wheel (Michie et al., 2011). The most common were persuasion $(n=10)$, enablement $(n=8)$ and education $(n=7)$. Next followed environmental restructuring $(n=4)$, coercion $(n=3)$, incentives $(n=2)$ and training $(n=1)$. None of the studies used the intervention function modelling or restriction (see Table 5).

The studies used between one and nine (median $=3$, mean $=4, \mathrm{SD}=3.05$ ) Behaviour Change Techniques specified in the Behaviour Change Technique Taxonomy v1 (Michie et al., 2013). Of the 93 BCTs available, only 23 were used, and of the 16 clustered groups, 12 were used (see Table 6). Furthermore, we had problems categorising one of the interventions (Bandyopadhyay and Dalvi 2017), leading us to suggest a new BCT (see Table 6), which we discuss in Section 4.3. The most commonly used BCTs were "social support (unspecified)" and "prompts/cues" ( $n=6$ each); followed by "feedback on behaviour" and "social comparisons", "self-monitoring", "instruction on how to perform the behaviour" ( $n=4$ each); "discrepancy between current behaviour and goal", "monitoring of behaviour by others without feedback", "feedback on outcomes of behaviour", "habit reversal" and "restructuring the social environment" ( $n=3$ each); "social reward" and "social incentive" ( $n=2$ each); and "action planning", "social support (emotional)", "salience of consequences", "behavioural practice/rehearsal", "behaviour substitution", "credible source", "conserving mental resources", "restructuring the physical environment" and "distractions and adding objects to the environment" ( $n=1$ each). 
Table 3. Overall assessment of study quality. Scale used to rate each category was: 0 (not at all), 1 (fulfils category criterion but with low reliability or validity), 2 (fulfils criterion with reasonable reliability and validity) and 3 (fulfils criterion with high reliability and validity), except for "other aggravating circumstances", rated 0 (major aggravating circumstances), 1 (aggravating circumstances), 2 (minor aggravating circumstances) and 3 (no aggravating circumstances).

\begin{tabular}{|c|c|c|c|c|c|c|c|}
\hline Study & $\begin{array}{c}\text { Measuring } \\
\text { Before/After/Baseline }\end{array}$ & Control Group & $\begin{array}{l}\text { Longitudinal } \\
\text { Follow-Up }\end{array}$ & $\begin{array}{l}\text { Respondents Match } \\
\text { the Target Group }\end{array}$ & $\begin{array}{c}\text { Substantial } \\
\text { Quantitative Results } \\
\end{array}$ & $\begin{array}{c}\text { Substantial } \\
\text { Qualitative Results }\end{array}$ & $\begin{array}{c}\text { Other Aggravating } \\
\text { Circumstances }\end{array}$ \\
\hline Bandyopadhyay and Dalvi 2017 & 1 & 0 & 0 & 2 & 1 & 0 & 2 \\
\hline Comber et al., 2013 & 1 & 0 & 0 & 0 & 0 & 1 & 1 \\
\hline Farr-Wharton et al., 2014a & 0 & 0 & 0 & 0 & 0 & 1 & 0 \\
\hline Farr-Wharton et al., 2014b & 0 & 0 & 0 & 0 & 0 & 1 & 0 \\
\hline Fujita et al., 2014 & 0 & 0 & 0 & 0 & 0 & 0 & 0 \\
\hline Ganglbauer et al., 2015 & 0 & 0 & 1 & 1 & 0 & 0 & 1 \\
\hline Lim et al., 2017 Part 1 & 0 & 0 & 0 & 1 & 0 & 1 & 0 \\
\hline Lim et al., 2017 Part 2 & 0 & 0 & 0 & 1 & 0 & 0 & 0 \\
\hline Oliveira et al., 2016 & 3 & 3 & 0 & 0 & 1 & 1 & 1 \\
\hline Pohl et al., 2017 & 0 & 0 & 0 & 0 & 1 & 0 & 0 \\
\hline Thieme et al., 2012 & 1 & 0 & 0 & 0 & 0 & 1 & 1 \\
\hline $\begin{array}{l}\text { Comber and Thieme } 2013 \\
\text { Woolley et al., } 2016\end{array}$ & 1 & 0 & 0 & 0 & 1 & 0 & 0 \\
\hline Young et al., 2017 & 1 & 0 & 1 & 1 & 1 & 0 & 0 \\
\hline Young et al., 2018 & 1 & 0 & 1 & 1 & 1 & 0 & 0 \\
\hline Zapico et al., 2016 & 3 & 2 & 1 & 2 & 2 & 0 & 1 \\
\hline
\end{tabular}

Table 4. Presence of a capability, opportunity, motivation, behaviour (COM-B) component in an intervention is indicated with an $\mathrm{x}$.

\begin{tabular}{|c|c|c|c|c|c|c|c|}
\hline Reference & Capability-Physical & Capability-Psychological & Opportunity-Physical & Opportunity-Social & Motivation-Reflective & Motivation-Automatic & Sum \\
\hline Bandyopadhyay and Dalvi 2017 & & & & $\mathrm{x}$ & $\mathrm{x}$ & $\mathrm{x}$ & 3 \\
\hline Comber et al., 2013 & & $\mathrm{x}$ & & $\mathrm{x}$ & $\mathrm{x}$ & $\mathrm{x}$ & 4 \\
\hline Farr-Wharton et al., 2014a & & & $\mathrm{x}$ & & & & 1 \\
\hline Farr-Wharton et al., 2014b & & $\mathrm{x}$ & $\mathrm{x}$ & & & & 2 \\
\hline Fujita et al., 2014 & & $\mathrm{x}$ & & & $\mathrm{x}$ & $\mathrm{x}$ & 3 \\
\hline Ganglbauer et al., 2015 & & & & & $\mathrm{x}$ & & 1 \\
\hline Lim et al. Part 1, 2017 & & $\mathrm{x}$ & $\mathrm{x}$ & $\mathrm{x}$ & & $\mathrm{x}$ & 4 \\
\hline Lim et al. Part 2, 2017 & & & & & $\mathrm{x}$ & & 1 \\
\hline Oliveira et al., 2016 & & & $\mathrm{x}$ & & & & 1 \\
\hline Pohl et al., 2017 & & & $\mathrm{x}$ & & & & 1 \\
\hline $\begin{array}{l}\text { Thieme et al., } 2012 \\
\text { Comber and Thieme } 2013\end{array}$ & & $\mathrm{x}$ & & $x$ & $\mathrm{x}$ & $\mathrm{x}$ & 4 \\
\hline Woolley et al., 2016 & & & $\mathrm{x}$ & & & & 1 \\
\hline Young et al., 2017 & & $\mathrm{x}$ & $\mathrm{x}$ & & & & 2 \\
\hline Young et al., 2018 & & $\mathrm{x}$ & $\mathrm{x}$ & & & & 2 \\
\hline Zapico et al., 2016 & & & & & $\mathrm{x}$ & & 1 \\
\hline Sum & 0 & 7 & 8 & 4 & 7 & 5 & 31 \\
\hline
\end{tabular}


Table 5. Presence of intervention function in an intervention is indicated with an $x$

\begin{tabular}{|c|c|c|c|c|c|c|c|c|c|c|}
\hline Reference & Education & Persuasion & Incentives & Coercion & Training & Enablement & Modelling & Environmental Restructuring & Restriction & Sum \\
\hline Bandyopadhyay and Dalvi 2017 & $\mathrm{x}$ & $\mathrm{x}$ & & $\mathrm{x}$ & & & & & & 3 \\
\hline Comber et al., 2013 & & $x$ & $\mathrm{x}$ & $\mathrm{x}$ & & & & & & 3 \\
\hline Farr-Wharton et al., 2014a & & & & & & $\mathrm{x}$ & & & & 1 \\
\hline Farr-Wharton et al., 2014b & $x$ & & & & & $x$ & & $\mathrm{x}$ & & 3 \\
\hline Fujita, et al., 2014 & $\mathrm{x}$ & $\mathrm{x}$ & & & & & & & & 2 \\
\hline Ganglbauer et al., 2015 & & $\mathrm{x}$ & & & & & & & & 1 \\
\hline Lim et al. Part 1, 2017 & $\mathrm{x}$ & $x$ & & & & $\mathrm{x}$ & & & & 3 \\
\hline Lim et al. Part 2, 2017 & & $\mathrm{x}$ & & & & & & & & 1 \\
\hline Oliveira et al., 2016 & & & & & $x$ & $x$ & & $x$ & & 3 \\
\hline Pohl et al., 2017 & & & & & & $\mathrm{x}$ & & $\mathrm{x}$ & & 2 \\
\hline $\begin{array}{l}\text { Thieme et al., } 2012 \\
\text { Comber and Thieme } 2013\end{array}$ & & $\mathrm{x}$ & $\mathrm{x}$ & $\mathrm{x}$ & & & & & & 3 \\
\hline Woolley et al., 2016 & & & & & & & & $\mathrm{x}$ & & 1 \\
\hline Young et al., 2017 & $\mathrm{x}$ & $x$ & & & & $x$ & & & & 3 \\
\hline Young et al., 2018 & $x$ & $x$ & & & & $x$ & & & & 3 \\
\hline Zapico et al., 2016 & $\mathrm{x}$ & $\mathrm{x}$ & & & & $\mathrm{x}$ & & & & 3 \\
\hline Sum & 7 & 10 & 2 & 3 & 1 & 8 & 0 & 4 & 0 & 35 \\
\hline
\end{tabular}


Table 6. Presence of a behaviour change technique (BCT) in an intervention is indicated with an $\mathrm{x}$. Numbering used is the same as in the Behaviour Change Taxonomy v1.

\begin{tabular}{|c|c|c|c|c|c|c|c|c|c|c|c|c|c|c|c|c|}
\hline & 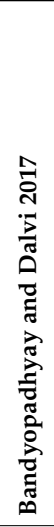 & 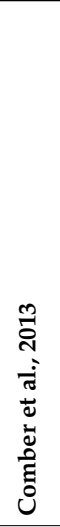 & 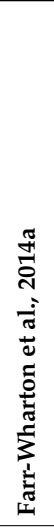 & 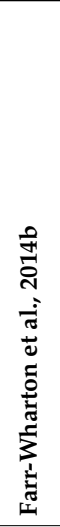 & 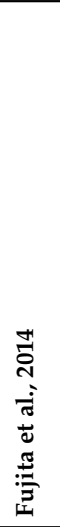 & 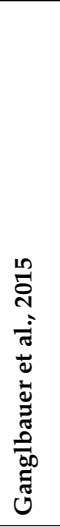 & 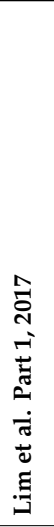 & 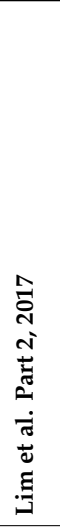 & 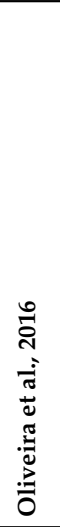 & 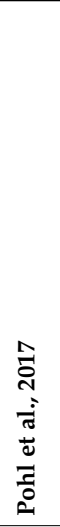 & 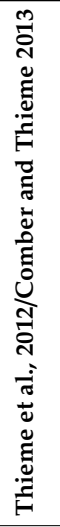 & 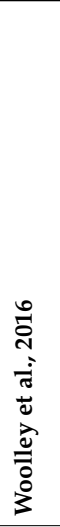 & 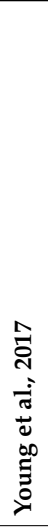 & 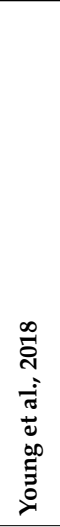 & 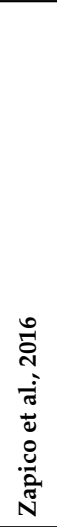 & $\Xi$ \\
\hline 1. Goals and planning & & & & & & & & & & & & & & & & 4 \\
\hline 1.4. Action planning & & & & & & & & & $\mathrm{x}$ & & & & & & & 1 \\
\hline 1.6. Discrepancy between current behavior and goal & & & & & & $\mathrm{x}$ & & $\mathrm{x}$ & & & & & & & $\mathrm{x}$ & 3 \\
\hline 2. Feedback and monitoring & & & & & & & & & & & & & & & & 15 \\
\hline 2.1. Monitoring of behavior by others without feedback & $\mathrm{x}$ & $\mathrm{x}$ & & & & & & & & & $\mathrm{x}$ & & & & & 3 \\
\hline 2.2. Feedback on behaviour & $\mathrm{x}$ & $\mathrm{x}$ & & & & & & $\mathrm{x}$ & & & $\mathrm{x}$ & & & & $\mathrm{x}$ & 5 \\
\hline 2.3. Self-monitoring of behaviour & & $\mathrm{x}$ & & & & $\mathrm{x}$ & & & & & $\mathrm{x}$ & & & & $\mathrm{x}$ & 4 \\
\hline 2.7. Feedback on outcome(s) of behavior & & & & & $\mathrm{x}$ & & $\mathrm{x}$ & & & & & & & & $\mathrm{x}$ & 3 \\
\hline 3. Social support and disapproval $(* *)$ & & & & & & & & & & & & & & & & 7 \\
\hline 3.1. Social support (unspecified) & & $\mathrm{x}$ & & & & $\mathrm{x}$ & $\mathrm{x}$ & & & & $\mathrm{x}$ & & $\mathrm{x}$ & $\mathrm{x}$ & & 6 \\
\hline 3.3. Social support (emotional) & & & & & & & $\mathrm{x}$ & & & & & & & & & 1 \\
\hline 3.4 $\left(^{*}\right)$. Social or public disapproval & $\mathrm{x}$ & & & & & & & & & & & & & & & \\
\hline 4. Shaping knowledge & & & & & & & & & & & & & & & & 4 \\
\hline 4.1. Instruction on how to perform the behavior & & & & & & & $\mathrm{x}$ & & $\mathrm{x}$ & & & & $\mathrm{x}$ & $\mathrm{x}$ & & 4 \\
\hline 5. Natural consequences & & & & & & & & & & & & & & & & 1 \\
\hline $\left.5.2^{* *}\right)$. Salience of consequences & $\mathrm{x}$ & & & & & & & & & & & & & & & 1 \\
\hline 6. Comparison of behaviour & & & & & & & & & & & & & & & & 5 \\
\hline 6.2. Social comparison & $\mathrm{x}$ & $\mathrm{x}$ & & & & & $\mathrm{x}$ & $\mathrm{x}$ & & & $\mathrm{x}$ & & & & & 5 \\
\hline 7. Associations & & & & & & & & & & & & & & & & 6 \\
\hline 7.1. Prompts/cues & $\mathrm{x}$ & & $\mathrm{x}$ & $\mathrm{x}$ & & & $\mathrm{x}$ & & $\mathrm{x}$ & & & $\mathrm{x}$ & & & & 6 \\
\hline 8. Repetition and substitution & & & & & & & & & & & & & & & & 5 \\
\hline 8.1. Behavioral practice/rehearsal & & & & & & & & & $\mathrm{x}$ & & & & & & & 1 \\
\hline 8.2. Behavior substitution & & & & & & & & & $\mathrm{x}$ & & & & & & & 1 \\
\hline 8.4. Habit reversal & & $\mathrm{x}$ & & & & & & & $\mathrm{x}$ & & $\mathrm{x}$ & & & & & 3 \\
\hline 9. Comparison of outcomes & & & & & & & & & & & & & & & & 1 \\
\hline 9.1. Credible source & & & & & & & & & & & & & & & $\mathrm{x}$ & 1 \\
\hline 10. Reward and threat & & & & & & & & & & & & & & & & 4 \\
\hline 10.4. Social reward & & $\mathrm{x}$ & & & & & & & & & $\mathrm{x}$ & & & & & 2 \\
\hline 10.5. Social incentive & & $\mathrm{x}$ & & & & & & & & & $\mathrm{x}$ & & & & & 2 \\
\hline 11. Regulation & & & & & & & & & & & & & & & & 1 \\
\hline 11.3. Conserving mental resources & & & & & & & & & $\mathrm{x}$ & & & & & & & 1 \\
\hline 12. Antecedents & & & & & & & & & & & & & & & & 6 \\
\hline 12.1. Restructuring the physical environment & & & & $\mathrm{x}$ & & & & & & & & & & & & 1 \\
\hline 12.2. Restructuring the social environment & $\mathrm{x}$ & $\mathrm{x}$ & & & & & & & & & $\mathrm{x}$ & & & & & 3 \\
\hline 12.4 Distractions & & & & & & & & & $\mathrm{x}$ & & & & & & & 1 \\
\hline 12.5. Adding objects to the environment & & & & & & & & & & $\mathrm{x}$ & & & & & & 1 \\
\hline 13. Identity & & & & & & & & & & & & & & & & 0 \\
\hline 14. Scheduled consequences & & & & & & & & & & & & & & & & 0 \\
\hline 15. Self-belief & & & & & & & & & & & & & & & & 0 \\
\hline 16. Covert learning & & & & & & & & & & & & & & & & 0 \\
\hline SUM & 7 & 9 & 1 & 2 & 1 & 3 & 6 & 3 & 8 & 1 & 9 & 1 & 2 & 2 & 5 & 60 \\
\hline $\begin{array}{l}(*) . \text { New BCT, see Section } 4.3 \\
\left({ }^{* *}\right) \text {. Modified BCT, see Section } 4.3\end{array}$ & & & & & & & & & & & & & & & & \\
\hline
\end{tabular}

\section{Discussion}

In this paper, we present results from a systematic literature review focused on the status of current scientific knowledge of digital behaviour change interventions for more sustainable food consumption practices. To summarise our findings, it is clear that knowledge about which digital interventions work and why is inconclusive and the field remains to be explored. We carried out a systematic search for peer-reviewed research on the topic, and found a total of 32 papers. Of these, only 15 were included in our corpus (see Figure 1), since only these had any evaluation of any kind (presenting empirical results) 
from a behaviour change perspective, even when we set a low requirement for including the studies. It was our conscious choice to stretch the criteria for including papers in this literature review. This decision was taken to ensure that we did not miss any relevant studies. While we have only included studies that present empirical results that make claims in terms of altered food behaviours, all of these 15 studies raise concerns when evaluated from the perspective of whether they led to long-term behaviour change or not. All studies have problems of a methodological nature; the setup of most studies could not even hope to answer the question of if and why they lead to long-term behaviour change, for example due to lack of a control group, lack of a baseline, problems with how variables are defined or measured, length of the study, longitudinal follow-ups, low number of participants, participants not matching the target group or consideration of other possible/likely causes of effects measured. We recognise that the goal of several of these studies was (probably) of an exploratory or "designerly" nature, but we also recognise the need to do follow-up studies examining where actual behaviour change is evaluated in a systematic way.

\subsection{Results in Comparison to Other Behavioural Change Studies}

Since our interest lies in understanding the current knowledge on digital behavioural change interventions for sustainable food consumption practices, we analysed primary studies in our corpus using the Behaviour Change Wheel (BCW) [10] framework. We compared the results of this review with three other reviews from different areas using either the Behaviour Change Wheel or the Behaviour Change Technique Taxonomy v1, concerning interventions for sedentary behaviour [14], transportation behaviour [13] and gamified mobile apps for health [3].

We found that there were primarily two groups of behaviour change techniques that stood out when compared to the other reviews. The first was feedback and monitoring, which was the most commonly used behaviour change technique used in this review, accounting for $25 \%$ of the interventions, which can be compared to $16 \%$ for sedentary behaviour [14] and 13\% for gamified health apps [3]. As noted by Edwards et al. [3], a wide range of studies have shown that feedback and monitoring are effective techniques for achieving behaviour change, and that a clear link can be made to a theoretical base in control theory. Control theory also suggests that goal setting combined with feedback and monitoring is effective for achieving behaviour change [3]. Therefore, it is interesting to note that of all BCTs coded, the goals and planning category was only coded four times (1\%), which can be compared to $28 \%$ for the study on sedentary behaviour [14] and $10 \%$ for the study on gamified health apps [3]. This could indicate that goals and planning is a theory-based type of intervention with high potential that has not yet been explored within the area of digital behaviour change interventions to change sustainable food consumption practices. However, the fact that certain interventions are successful at changing behaviours in one area does not necessarily entail that the corresponding interventions are successful at changing behaviours in a different area. Thus, it might not be valid to compare interventions in sedentary or transportation behaviour to interventions in food-related behaviour. Moreover, food-related behaviour connected to sustainability denotes a broader range of behaviours compared to, for example, sedentary behaviour. Although our review reveals that most of the literature deals with food waste behaviour, it also contains articles relating to significantly different types of behaviour, e.g., food purchasing behaviour.

The mean number of behaviour change techniques used was relatively low (mean $=3.93$, median $=3$, range 1-9) compared to the interventions in the study on gamified health (median $=14$, range 5-22) [3] and sedentary behaviour (mean =9.37) [14]. A previous meta-analysis on internet-based interventions suggested that the number of techniques used was directly related to outcomes [18]. This indicates that combining various behaviour change techniques (BCTs) in one intervention could be more effective in terms of behaviour change outcomes, but at the same time, it becomes more difficult to draw conclusions about why a particular intervention worked. 


\subsection{Behaviours Versus Social Practices}

It can be argued that digital behaviour change interventions are not enough to achieve reduced environmental impact. Many strategies are based on perceptions that consumer attitudes and actions are rational and that consumers act as individuals [19]. These perceptions are challenged from a sociological perspective, for example, arguing that instead of using behaviour as a unit of analysis, a social practice lens is more relevant and has greater potential to reduce environmental impact (e.g., [20]). A focus on individual choices and behaviours can, for example, make us miss the opportunities and constraints that lie in the social structure and context. From the perspective of social practitioners, there are several factors that influence how we as consumers act and perform practices with other people [19].

The benefit of using a social practice theory approach is that it is not enough to judge people's individual choices; we must also see how they are related to many other things on different levels in society [21]. These may include the design of a store or a city, laws and regulations, and how we value the food. Approaches based on social practice theory attach importance to habits, routines, competencies, social relations, conventions, norms, rules, materials and structures in the environment. It is important to keep the social practice perspective in mind when designing digital interventions within the food area, because it stimulates reflections on their potential and may also emphasise issues of scalability. Furthermore, keeping this perspective in mind may also facilitate an integration of behaviour interventions with structural and systemic changes. Perhaps the outer layer of the BCW, the "policy types" that can be used or that deliver intervention functions, could bridge the gap between individual behaviours and a larger societal focus. However, notably, none of the studies included in our review explicitly touch upon this outer layer of the BCW or reflect on the behaviour change interventions in relation to other levels in society.

\subsection{Extending the Behavior Change Technique Taxonomy}

One of the papers we analysed (Bandyopadhyay and Dalvi 2017) made use of techniques that were hard to fit into the Behaviour Change Technique Taxonomy v1 [12]. We use that paper as a starting point for a discussion regarding two proposed additions to the taxonomy as well as some more general reflections about it. The main component of the interactive installation called "The Darker Side", which Bandyopadhyay and Dalvi (2017) designed, deployed and tested, was a waste bin in a university food canteen that weighed the food that was thrown away and displayed a personalised message consisting of text and an image on a 40 inch screen: "The messages were designed to evoke pain and give a moderate level of aversive feedback. The messages changed from low to high level of aversion depending upon the amount of food thrown (wasted) by an individual.... A minimum threshold of $100 \mathrm{~g}$ [helped eliminate] instances of inedible leftovers being [thrown away]" (Bandyopadhyay and Dalvi 2017, p. 239).

This system stood out, since it was the only system that was explicitly aimed at making users uncomfortable by inducing feelings of shame, against the backdrop of "around 3000 children in India dying every day from illness related to poor diet" (Bandyopadhyay and Dalvi 2017, pp. 235-236). When more than $100 \mathrm{~g}$ of food was thrown away, the face of a child "staring at the camera" morphed from happy to sad and from healthy to malnourished.

With inspiration from this paper, we suggest that it would be possible in this case to define two more BCTs related to "personal and public shaming" that are not sufficiently covered by the Behaviour Change Technique Taxonomy v1. "Personal shaming" is the shaming of an individual in his/her own eyes by problematising his/her behaviour and mirroring it back (in Bandyopadhyay and Dalvi (2017) by connecting the behaviour of throwing away excessive amounts of food to the plight of starving children). The goal is that the individual will realise, "When I perform this behaviour, I am not a good person". "Public shaming", on the other hand, is the shaming of an individual by allowing others to observe the negative feedback the person receives. The exact setup (e.g., how many others could see the screen, etc.) is unclear even from a close reading of that paper, but it is evident that public shaming is very much in line with the intentions of the designers who, for example, applied "Panopticon", 
"a feeling of being observed, under surveillance" (Bandyopadhyay and Dalvi 2017, p. 239), as an awareness-raising strategy. The authors also mention that they build upon the results of another paper in our study, the paper by Comber and Thieme (2012), whose design of the "BinCam" system resulted in self-reflection and "feelings of shame", although that was not their intention.

Public shaming as described above is related to but does not exactly match any of the existing BCTs. We thus suggest that that the group "social support" should be broadened and renamed "social support and disapproval" and that a fourth BCT should be added, "social or public disapproval". Our proposed definition and an example of this new BCT are as follows:

Definition 1. Arrange or provide emotional social disapproval (e.g., from friends, relatives, colleagues, "buddies", staff members or strangers) for performance of the behaviour.

Example 1. Publicly divulge individual travel-related $\mathrm{CO}_{2}$ emissions in the workplace for all employees.

Personal shaming, as described above, is also related to but does not exactly match any of the existing BCTs. Several of the BCTs in the "natural consequences" group could be possible matches (e.g., "information about health consequences", "salience of consequences" and "information about social and environmental consequences"), but all of these aim for cognitive functions rather than emotional impact. While we considered proposing a new BCT, we instead opted for a minor alteration of an existing BCT, "salience of consequences" (additions in bold):

Definition 2. Use methods specifically designed to emphasise the consequences of performing the behaviour with the aim of making them more memorable or emotionally impactful (goes beyond informing about consequences).

Example 2. Connect long-haul flights to images of shrinking ice floes and starving polar bears.

It should be noted, that our proposed addition to "salience of consequences" covers the fact that the purpose of the installation "The Darker Side" is not to provide information (as privileged Indians already know that many children are starving in India), but rather to invoke a feeling of shame when individuals gratuitously waste food.

We end this deliberation with a few more general reflections about the Behaviour Change Technique Taxonomy v1 [12]. One reflection already mentioned above is that existing BCTs typically aim for information-oriented cognitive functions rather than emotional impact. This means that most of the BCTs have active verbs of the type "introduce", "inform", "present", "establish", "arrange", "prompt", "draw attention to", "raise awareness of", "observe", "record", "monitor", "provide feedback", "review", etc. No BCTs explicitly aim for emotional impact, such as inducing pride, joy, empathy, shame, (emotional) pain or fear.

Another observation is that the origin of the BCTs [12] might have influenced their form. While the large group of people who had a hand in developing the BCTs came from many different areas, broadly speaking they all had a background in two fields, health and psychology. All existing examples come from the area of health, and that is also where the Behaviour Change Wheel and Behaviour Change Technique Taxonomy have, for the most part, been used to date. Our study of digital behaviour change interventions for sustainable food consumption practices thus belongs to the minority of studies that use these frameworks to study non-health-related behaviour change interventions. This observation opens up interesting developments of the BCTs when applied in non-health-related areas.

Another observation is that only 2 studies were conducted in a non-Western context (India, Indonesia) and of the remaining 13 studies, 2 came from Australia and 11 from various European countries. We also note that we ourselves were challenged by a study (Bandyopadhyay and Dalvi 2017) that was not conducted in a Western, educated, industrialised, rich and democratic, i.e., WEIRD, context [22]. This study did not shy away from evoking pain and inducing feelings such as shame and guilt as explicit design strategies, or from referring to surveillance and the Panopticon in a 
positive light. When we attempted to formulate a new BCT, "social or public disapproval", we were challenged to think of an existing example of a designed behaviour change intervention that attempts to provide emotional social disapproval. Such systems are seldom or never built for a variety of reasons, although some researchers have begun to examine discomfort [23] or "uncomfortable user experiences", e.g., to "explore the deliberate engineering of discomfort as a way to create intense, memorable interactions and engage challenging themes" [24]. Where Benford et al. [24] work in the intersection of human-computer interactions and performance studies, we imagine that it could be an insurmountable challenge to get ethical approval to conduct medical or health-related studies that explore the effects of "uncomfortable experiences" or that induce shame, pain or fear.

\section{Conclusions and Future Research}

In light of the systematic literature review presented in this paper on digital behaviour change interventions for sustainable food consumption practices, it is clear that knowledge regarding which digital interventions work and the reasons for why, is inconclusive and the field remains to be more systematically and rigorously explored. Hence, it is too early to give any recommendations to policy makers. However, recommendations for future research can be made, that can serve as guidelines for research funding agencies. First of all, there is a need for more well-planned, well-executed and focused studies in this area. To fill the need for more rigorous studies, several issues must be addressed. For example, there is a need for studies measuring actual changes in behaviour as well as the effects of these (potential) changes. This could be in relation to such sustainability measures as the amount of reduced food waste or energy saved by behaviour change, and should include the possible negative sustainability aspects of the technology itself e.g., in the form of e-waste. In terms of sustainable food consumption practices, there is a need for studies focusing on aspects other than food waste, which was the dominant behaviour addressed in the studies in our corpus. This could include affecting the type of food consumed (i.e., more climate friendly, more ecological, less energy used, more plant-based, alternative sources for protein (insects), locally produced), or studies outside of individual household behaviours such as practices in restaurants, school kitchens or canteens. Especially, we see a need for more studies about reducing the greenhouse gas emissions from food, since, as mentioned in the introduction, the climate impact of the food system is substantial. There is also an opportunity to do more studies on existing commercial systems, like Karma, Deedster or Olio. Furthermore, there is a clear lack of studies with control groups and longitudinal studies measuring behaviour change over longer time periods.

Our review has shown that many studies fail in connecting interventions to theoretical concepts or frameworks, such as the Behaviour Change Wheel $[10,11]$ and the Behaviour Change Technique Taxonomy v1 [12]. Since the BCW and BCT have mostly been used in the area of health interventions, it is interesting to study how they work for sustainability interventions. There is a difference between health interventions and sustainability interventions, in that the latter is concerned with effects often occurring somewhere else, to someone else, at some other time, rather than direct effects on one's own health, for example. There might be a need to include other BCTs that are more relevant for these kinds of behavioural change interventions.

We conclude that new interventions from now on should be better grounded. That is, they should be based on a behaviour change theory and should specify what the target behaviour is as well as be better evaluated. We believe that the time has come to move from exploratory studies to more rigorous testing of which interventions actually lead to behaviour change.

Author Contributions: All authors contributed equally to all parts of the review. B.H., project administration; B.H., funding acquisition.

Funding: This research was funded by Formas, the Swedish Research Council for sustainable development, grant number FR-2017/0009.

Acknowledgments: A sincere thank you is given to the reviewers who gave constructive feedback and comments on earlier versions of this paper, and to Rosa Lönneborg for search strategy support. 
Conflicts of Interest: The authors declare no conflict of interest.

\section{Appendix A. Papers Included in the Review}

1. Bandyopadhyay, J., Dalvi, G., 2017. Can Interactive Installations Bring About Behaviour Change? Using Interactive Installation to Change Food Waste Behaviours BT-Research into Design for Communities, Volume 2, in: Chakrabarti, A., Chakrabarti, D. (Eds.), Springer Singapore, Singapore, pp. 235-245.

2. Comber, R., Thieme, A., 2013. Designing beyond habit: opening space for improved recycling and food waste behaviors through processes of persuasion, social influence and aversive affect. Pers. ubiquitous Comput. 17, 1197-1210.

3. Comber, R., Thieme, A., Rafiev, A., Taylor, N., Krämer, N., Olivier, P., 2013. BinCam: Designing for engagement with Facebook for behavior change, in: IFIP Conference on Human-Computer Interaction. Springer, pp. 99-115.

4. Farr-Wharton, G., Choi, J.H.-J., Foth, M., 2014a. Technicolouring the Fridge: Reducing Food Waste Through Uses of Colour-coding and Cameras, in: Proceedings of the 13th International Conference on Mobile and Ubiquitous Multimedia, MUM '14. ACM, New York, NY, USA, pp. 48-57. https://doi.org/10.1145/2677972.2677990

5. Farr-Wharton, G., Choi, J.H.-J., Foth, M., 2014b. Food talks back: exploring the role of mobile applications in reducing domestic food wastage, in: Proceedings of the 26th Australian Computer-Human Interaction Conference on Designing Futures: The Future of Design. ACM, pp. 352-361.

6. Fujita, H., Koide, N., Santoso, A.D., Tsubaki, H., Iijima, W., Satria, W.D., Susanto, J.P., Kitagawa, G., 2014. Mobile application development for environmental informatics and feedback on cooking oil use and disposal in Indonesia, in: 2014 2nd International Conference on Technology, Informatics, Management, Engineering \& Environment. pp. 29-33. https://doi.org/10.1109/TIME-E.2014.7011587

7. Ganglbauer, E., Fitzpatrick, G., Güldenpfennig, F., 2015. Why and What Did We Throw out?: Probing on Reflection Through the Food Waste Diary, in: Proceedings of the 33rd Annual ACM Conference on Human Factors in Computing Systems, CHI '15. ACM, New York, NY, USA, pp. 1105-1114. https://doi.org/10.1145/2702123.2702284

8. Lim, V., Funk, M., Marcenaro, L., Regazzoni, C., Rauterberg, M., 2017. Designing for action: An evaluation of Social Recipes in reducing food waste. Int. J. Hum. Comput. Stud. 100, 18-32. https://doi.org/10.1016/J.IJHCS.2016.12.005

9. Oliveira, L., Mitchell, V., May, A., 2016. Reducing temporal tensions as a strategy to promote sustainable behaviours. Comput. Human Behav. 62, 303-315. https://doi.org/https://doi.org/10. 1016/j.chb.2016.04.004

10. Pohl, M., Weißenböck, E., Wauschek, S.G.R., Kalleitner-Huber, M., Mraz, G., Bernhofer, G., 2017. Designing cooling stations for food sharing in public spaces, in: 2017 Sustainable Internet and ICT for Sustainability (SustainIT). pp. 1-8. https://doi.org/10.23919/SustainIT.2017.8379793

11. Thieme, A., Comber, R., Miebach, J., Weeden, J., Kraemer, N., Lawson, S., Olivier, P., 2012. We've bin watching you: designing for reflection and social persuasion to promote sustainable lifestyles, in: Proceedings of the SIGCHI Conference on Human Factors in Computing Systems. ACM, pp. 2337-2346.

12. Woolley, E., Garcia-Garcia, G., Tseng, R., Rahimifard, S., 2016. Manufacturing Resilience Via Inventory Management for Domestic Food Waste. Procedia CIRP 40, 372-377. https: //doi.org/10.1016/J.PROCIR.2016.01.070

13. Young, C.W., Russell, S. V, Robinson, C.A., Chintakayala, P.K., 2017. Sustainable Retailing Influencing Consumer Behaviour on Food Waste. Bus. Strateg. Environ. 27, 1-15. https: //doi.org/10.1002/bse.1966 
14. Young, W., Russell, S. V., Robinson, C.A., Barkemeyer, R., 2017. Can social media be a tool for reducing consumers' food waste? A behaviour change experiment by a UK retailer. Resour. Conserv. Recycl. 117, 195-203. https://doi.org/10.1016/J.RESCONREC.2016.10.016

15. Zapico, J.L., Katzeff, C., Bohné, U., Milestad, R., 2016. Eco-feedback Visualization for Closing the Gap of Organic Food Consumption, in: Proceedings of the 9th Nordic Conference on Human-Computer Interaction, NordiCHI '16. ACM, New York, NY, USA, p. 75:1-75:9. https: //doi.org/10.1145/2971485.2971507

\section{References}

1. Frison, E.A. From Uniformity to Diversity: A Paradigm Shift from Industrial Agriculture to Diversified Agroecological Systems; IPES: Louvain-la-Neuve, Belgium, 2016.

2. Steffen, W.; Richardson, K.; Rockström, J.; Cornell, S.E.; Fetzer, I.; Bennett, E.M.; Biggs, R.; Carpenter, S.R.; de Vries, W.; de Wit, C.A.; et al. Planetary boundaries: Guiding human development on a changing planet. Science 2015, 347, 1259855. [CrossRef] [PubMed]

3. Edwards, E.A.; Lumsden, J.; Rivas, C.; Steed, L.; Edwards, L.A.; Thiyagarajan, A.; Sohanpal, R.; Caton, H.; Griffiths, C.J.; Munafò, M.R.; et al. Gamification for health promotion: Systematic review of behaviour change techniques in smartphone apps. BMJ Open 2016, 6, e012447. [CrossRef] [PubMed]

4. Johnson, D.; Horton, E.; Mulcahy, R.; Foth, M. Gamification and serious games within the domain of domestic energy consumption: A systematic review. Renew. Sustain. Energy Rev. 2017, 73, 249-264. [CrossRef]

5. Brynjarsdottir, H.; Håkansson, M.; Pierce, J.; Baumer, E.; DiSalvo, C.; Sengers, P. Sustainably Unpersuaded: How Persuasion Narrows Our Vision of Sustainability. In Proceedings of the SIGCHI Conference on Human Factors in Computing Systems, CHI '12, Austin, TX, USA, 5-10 May 2012; ACM: New York, NY, USA, 2012; pp. 947-956.

6. Alfredsson, E.C. “Green” consumption-No solution for climate change. Energy 2004, 29, 513-524. [CrossRef]

7. Hesselgren, M.; Hasselqvist, H. Giving car-free life a try: Designing seeds for changed practices. In Proceedings of the DRS 2016, Design Research Society 50th Anniversary Conference, Brighton, UK, 27-30 June 2016.

8. Hasselqvist, H.; Hesselgren, M.; Bogdan, C. Challenging the Car Norm: Opportunities for ICT to Support Sustainable Transportation Practices. In Proceedings of the 2016 CHI Conference on Human Factors in Computing Systems (CHI '16), San Jose, CA, USA, 7-12 May 2016.

9. Shrinivasan, Y.B.; Jain, M.; Seetharam, D.P.; Choudhary, A.; Huang, E.M.; Dillahunt, T.; Mankoff, J. Deep Conservation in Urban India and Its Implications for the Design of Conservation Technologies. In Proceedings of the SIGCHI Conference on Human Factors in Computing Systems, CHI '13, Paris, France, 27 April-2 May 2013; pp. 1969-1978.

10. Michie, S.; van Stralen, M.M.; West, R. The behaviour change wheel: A new method for characterising and designing behaviour change interventions. Implement. Sci. 2011, 6, 42. [CrossRef] [PubMed]

11. Michie, S.; Atkins, L.; West, R. The Behaviour Change Wheel: A Guide to Designing Interventions; Silverback: London, UK, 2014.

12. Michie, S.; Richardson, M.; Johnston, M.; Abraham, C.; Francis, J.; Hardeman, W.; Eccles, M.P.; Cane, J.; Wood, C.E. The Behavior Change Technique Taxonomy (v1) of 93 Hierarchically Clustered Techniques: Building an International Consensus for the Reporting of Behavior Change Interventions. Ann. Behav. Med. 2013, 46, 81-95. [CrossRef] [PubMed]

13. Arnott, B.; Rehackova, L.; Errington, L.; Sniehotta, F.F.; Roberts, J.; Araujo-Soares, V. Efficacy of behavioural interventions for transport behaviour change: Systematic review, meta-analysis and intervention coding. Int. J. Behav. Nutr. Phys. Act. 2014, 11, 133. [CrossRef] [PubMed]

14. Gardner, B.; Smith, L.; Lorencatto, F.; Hamer, M.; Biddle, S.J.H. How to reduce sitting time? A review of behaviour change strategies used in sedentary behaviour reduction interventions among adults. Health Psychol. Rev. 2016, 10, 89-112. [CrossRef] [PubMed]

15. Moher, D.; Liberati, A.; Tetzlaff, J.; Altman, D.G.; Altman, D.; Antes, G.; Atkins, D.; Barbour, V.; Barrowman, N.; Berlin, J.A.; et al. Preferred reporting items for systematic reviews and meta-analyses: The PRISMA statement. PLoS Med. 2009, 6, e1000097. [CrossRef] [PubMed] 
16. Wohlin, C. Guidelines for snowballing in systematic literature studies and a replication in software engineering. In Proceedings of the 18th International Conference on Evaluation and Assessment in Software Engineering, EASE'14, London, UK, 13-14 May 2014; ACM: New York, NY, USA, 2014; p. 38.

17. Higgins, J.P.; Green, S. Cochrane Handbook for Systematic Reviews of Interventions: Cochrane Book Series; Wiley-Blackwell: Chichester, UK, 2008. Available online: https://onlinelibrary.wiley.com/doi/book/10.1002/ 9780470712184 (accessed on 8 May 2019).

18. Webb, T.L.; Joseph, J.; Yardley, L.; Michie, S. Using the Internet to Promote Health Behavior Change: A Systematic Review and Meta-analysis of the Impact of Theoretical Basis, Use of Behavior Change Techniques, and Mode of Delivery on Efficacy. J. Med. Internet Res. 2010, 12, e4. [CrossRef] [PubMed]

19. Doyle, R.; Davies, A.R. Towards sustainable household consumption: Exploring a practice oriented, participatory backcasting approach for sustainable home heating practices in Ireland. J. Clean. Prod. 2013, 48, 260-271. [CrossRef]

20. Shove, E.; Walker, G. Governing transitions in the sustainability of everyday life. Res. Policy 2010, 39, 471-476. [CrossRef]

21. Evans, D.; McMeekin, A.; Southerton, D. Sustainable Consumption, Behaviour Change Policies and Theories of Practice. In The Habits of Consumption; Warde, A., Southerton, D., Eds.; Studies across Disciplines in the Humanities and Social Sciences 12; Helsinki Collegium for Advanced Studies: Helsinki, Finland, 2012; pp. 113-129.

22. Henrich, J.; Heine, S.J.; Norenzayan, A. The weirdest people in the world? Behav. Brain Sci. 2010, 33, 61-83. [CrossRef] [PubMed]

23. Halbert, H.; Nathan, L.P. Designing for Discomfort: Supporting Critical Reflection Through Interactive Tools. In Proceedings of the 18th ACM Conference on Computer Supported Cooperative Work \&; Social Computing, CSCW '15, Vancouver, BC, Canada, 14-18 March 2015; ACM: New York, NY, USA, 2015; pp. 349-360.

24. Benford, S.; Greenhalgh, C.; Giannachi, G.; Walker, B.; Marshall, J.; Rodden, T. Uncomfortable user experience. Commun. ACM 2013, 56, 66-73. [CrossRef] 